illusionment, or depression period. Viewed from the outside, though, these feelings can be seen as necessary to fulfilling the need for differentiation leading to the reorganization of community structures.

f. The issues on which differentiation are based are not consistent with pre-disaster community structures. Often, conflict develops between old structures reasserting themselves and emerging new structures. Emerging structures can cut across or generally be incompatible with existing structures, fostering competition for resources, opportunism, and political tensions. Sometimes old structures are destroyed in this process.

g. Because differentiation occurs around differences between people or community subsystems, it is possible to anticipate some differences and recognize others as they begin to emerge. These differences can be called community "cleavage planes." These cleavage planes are issues differences or issues around which competition, rivalry, and conflict is generated, and through which groups and systems are likely to move apart.

h. Understanding the dynamics of communities in disaster recovery and identifying cleavage planes can provide the basis for recovery planning and intervention designed to enable and support constructive differentiation, and can minimize conflict and competition with pre-disaster community structures. Intervention can enable recovery by fostering appropriate differentiation and bonding, and by anticipating and defusing cleavages and conflict.

i. Communities have a very strong internal drive to recover from disaster. It is the existence of this drive that usually defeats attempts at successful recovery imposed from the outside. Instead, the dynamics of the recovery process must be under- stood and accepted, and used to support the community's own recovery activity. Outside help can be effective in a community to assist people in identifying and understanding a larger view of their situation that goes beyond the understanding usually permitted by their personal experience and circumstances. Successful intervention can help a community develop and reform itself, carry-out recovery, and positively integrate the disaster into its history.

D. Recovery Strategies

1. An understanding of the dynamics and needs of communities in disaster recovery suggests several general strategies which can be effective in enabling recovery:

a. Reducing isolation;

b. Restoring a sense of self-control;

c. Forming groups and networks;

d. Enabling communication and information exchange;

e. Community development; and

f. Symbolic events.

\section{References}

Gartland K: The State of the Art: Recovery from Disaster and Emergencies. Article via Internet: CSV Disaster Support and Recovery Unit. Melbourne, Australia, 1993.

McKay J: Federal Emergency Management Agency (FEMA). Interview, Washington, D.C., 10 Janu- ary 1994.

Raphael B: When Disaster Strikes: How Individuals and Communities Cope With Catastrophe. New York: Basic Books, Inc., 1986.

Wraith R, Gordon R: Community Responses to Natural Disaster. Article via Internet: Department of Child and Family Psychiatry, Melbourne Royal Children's Hospital. Melbourne, Australia, 1993.

Wraith R, Gordon R: Long Term Human Responses to Disaster. Article via Internet: Department of Child and Family Psychiatry, Melbourne Roval Chit dren's Hospital. Melbourne, Australia, 1993.

\title{
Ethical Issues for Agencies and Service Providers
}

Judith K. Wells-Crowley, PhD

Medical Psychologist, lowa Methodist Hospital, Des Moines, Iowa USA

\section{The Challenge}

Disasters are extremely complex events that usually result in widespread destruction and distress. The ultimate aims of disaster intervention are first and foremost, humanitarian and compassionate. But, with our caring and good intentions, as professionals, we also must provide the highest caliber of knowledge and skills.

Providing service in the midst of a disaster is uniquely challenging. One is faced with the aftermath of such experiences as loss of home, food, utilities, employment, other resources and property; dislocation from family and community; and even, physical injury and death. Working with experiences such as these-and perhaps more to the point, doing so in the very midst of the chaosthe professional also faces a myriad of ethical issues. The challenge is to maintain excellence in our actions even in the midst of this chaos.

\section{Professional Versus \\ Nonprofessional Relationships}

Ethics are both the specific moral choices to be made by the individual in his/her relationship with others, as well as the rules or standards governing the conduct of the members of a profession. We can volunteer our energies in a disaster as private citizens (e.g., a psychologist sandbagging in a flood), or offer our services as a professional. When we participate as professionals, certain responsibilities automatically ensue, and these will include certain ethical obligations. It is of utmost importance that we are clear in our understanding of what, in each of our disciplines, constitutes a "professional relationship." For example, a simple action, such as giving advice or an opinion to a disaster victim, may create a professional relationship. And, with this, a host of ethical responsibilities also are created. 


\section{Exemplary Shared Standards Among Professionals}

\section{Competence}

The people whom we serve as professionals assume that we are competent to do what we are called to do, even in a disaster. Yet, we very well may find ourselves ill-prepared for some of the specific situations we may encounter. For example, a paramedic may be required to make medical decisions that go beyond his or her training or prior experiences. A mental health worker may be required to intervene in a situation of suicidality without specific training or prior experience in such.

As professionals, most of us have ethical guidelines regarding competence that limit our actions to those for which we are fully qualified by education, training, and/or experience. However, in a disaster, we may find ourselves called upon to serve in ways that push the boundaries of that education and experience. Furthermore, at the time, we may not have access to a colleague who more appropriately could serve the disaster victim, or at least offer consultation or supervision.

\section{Confidentiality}

Most professionals are bound ethically by a principle of confidentiality in relationships with those served. What happens to this principle when one literally is working "in the trenches?" In a disas- ter, one rarely is working alone with one victim. In fact, more often than not, one is working in the open with a crowd or in a makeshift facility with little to no privacy. Mental health workers may find themselves doing "curb-side counseling." Any worker may find him or herself being interviewed by the media. What minimal parameters are we going to set with respect to confidentiality? Is it practical to aspire to any in the midst of such life and death drama as may occur?

\section{Duties}

Special duties may accompany professional service. This might include the duty to warn others if an individual is potentially harmful to self or others. It might include the duty to report potentially harmful or illegal activity. At the very least, our efforts may include the duty to do no harm.

\section{Transitioning for Local Long-Term Service} In our effort to do no harm, we might ask ourselves what effects obtain not only from our actions, but also from our leaving at the end of our service. Most professionals volunteering in a disaster only will be able to participate in recovery efforts for a very limited time. What responsibilities do we have to the individuals whom we have met, aided, and served in a professional capacity? How do we assure ourselves that they will con- tinue to be provided the service that we have begun? One of the common ethical principles we share in one form or another, is the principle of interdisciplinary cooperation. It follows that individually we have an obligation to work smoothly with members of other professions and with our local counterparts. Individual and inter-agency cooperation becomes paramount when we are transitioning from external to local service. Making that transition is an ethical obligation for each of us as professionals. We must not simply assume that "someone will take care of it," or that "I did what I could, now it's someone else's turn."

\section{Excellence Through Ethics}

It is certain that disasters always will exist and, it is clear that ethical dilemmas will accompany these. As research data bases increase and theoretical models are being developed to guide our actions in disaster work, I encourage us also to look to our respective ethical codes to provide guidance for how that work will be practiced. It is one thing to conduct our professional work within the confines of a physically and emotionally structured environment. It is another to maintain the highest standards of our practice in the midst of a disaster. Those whom we serve always deserve our utmost professionalism. This is no less true in times of chaos.

\section{Lessons Learned from Research at Three-Mile Island and Goiania, Brazil} Daniel L. Collins, PhD

Lt. Colonel, United States Air Force Office of Scientific Research, Bolling AFB, D.C. USA

The views expressed are those of the author and do not reflect an official United States Air Force position.

A summary of the research findings associated with two ionizing radiation accidents were presented. The first accident occurred at Three Mile Island (TMI) in Pennsylvania and the second accident occurred in South America at Goiania, Brazil. The knowledge from these two unfortunate incidents pro- vides an interesting examination of the human stress response associated with ionizing radiation accidents. The knowledge obtained from the TMI accident (where very little, if any, radiation was released) was extended by studying the Goiania, Brazil accident (where four people died from radiation exposure).

More than 15 years have passed since the first major nuclear power plant accident in the United States occurred at Three Mile Island, Goldsboro, Pennsylvania. Understanding the psychological after-effects requires a thorough knowledge of the temporal antecedents, because they are an essential internal component of the Three Mile Island accident. Therefore, this presentation described the Three Mile Island accident; reviewed the major events preceding the psychological studies; and summarized the major psychological, behavioral, and neuroendocrine findings of field studies of the Three Mile Island residents.

The research findings at Three Mile Island were extended by studying the psychological stress sequel associated with an ionizing radiation accident, where a significant amount of radiation was released. At the invitation of the Brazilian government, a multidisciplinary field study was conducted in Goiania, Brazil, 3 1/2 years after an accident 